\title{
"Consumidores y ciudadanos" o el consumo como hipérbole
}

\author{
Rodrigo Moulian *
}

"La investigación como ensayo" es la modalidad genérica como Néstor García Canclini define a su libro "Consumidores y ciudadanos. Conflictos multiculturales de la globalización". (1995, Editorial Grijalbo, México, 198 páginas). El texto de García Canclini se compone de diez capítulos, concebidos -en su mayor parte-como ensayos autónomos unos de otros. En ellos aborda temas tales como el consumo como medio de integración y expresión de la identidad, las culturas urbanas en las grandes ciudades latinoamericanas, los métodos y perspectivas para la investigación de éstas, el funcionamiento del mercado audiovisual, los procesos de constitución y redefinición de la identidad en un mundo globalizado y el desarrollo de políticas culturales en América Latina en el contexto de la posmodernidad y la globalización.

El trabajo, de acuerdo a su autor, se halla a mitad de camino entre un libro de investigación y un conjunto de ensayos. Desde nuestra perspectiva, más que "la investigación como ensayo", su texto debería rotularse "el ensayo como investigación", toda vez que en él predomina una actividad reflexiva antes que el análisis o exposición de datos primarios originados en la propia investigación empírica. En "Consumidores y ciudadanos" encontramos la continuidad del trabajo de reflexión del autor sobre la cultura latinoamericana, cuyo antecedente bibliográfico más importante es "Culturas Híbridas".

Segūn García Canclini, la escena sociocultural actual se define a partir de cinco grandes procesos de transformación:

a) Un redimensionamiento de las instituciones y los circuitos de ejercicio de lo público: pérdida de peso de los organismos locales y nacionales en beneficio de los conglomerados empresariales de alcance transnacional.

b) La reformulación de los patrones de asentamiento y convivencia urbanos: del barrio a los condominios, de las interacciones próximas a la diseminación policéntrica de la mancha urbana. 
c) La reelaboración de lo propio, debido al predominio de los bienes y los mensajes procedentes de una economía y una cultura globalizadas.

d) La consiguiente redefinición del sentido de pertenencia e identidad, organizado cada vez menos por lealtades locales o nacionales y más por la participación en comunidades transnacionales desterritorializadas.

e) El pasaje del ciudadano como representante de una opinión pública al ciudadano como consumidor.

Este último punto es la principal tesis del libro. García Canclini propone que, hoy, las modalidades de consumo constituyen la carta de ciudadanía, es decir que el consumo es la principal forma de integración social, a diferentes grupos de pertenencia, y de figuración en el espacio público. Su hipótesis de base es que cuando seleccionamos los bienes y nos apropiamos de ellos definimos lo que consideramos públicamente valioso, las maneras como nos integramos y distinguimos en la sociedad. Por supuesto, aquí ni el concepto de ciudadanía es definido desde un perspectiva jurídico-política, ni en concepto de consumo es comprendido desde la racionalidad económica. Ambos son leídos desde una mirada culturológica. Según García Canclini, ser ciudadanos no tiene que ver sólo con los derechos reconocidos por los aparatos estatales a quienes nacieron en un territorio, sino con las prácticas sociales y culturales que dan sentido de pertenencia. $Y$ hoy esto se resuelve más por la vía del mercado que del Estado, a través del consumo. Este es definido como "el conjunto de los procesos socioculturales en que se realizan la apropiación y uso de los productos". El consumo no es visto, por lo tanto, como la mera posesión individual de objetos, sino como la apropiación colectiva, en relaciones de solidaridad y distición con los otros, de bienes que junto con satisfacer las necesidades, sirven para enviar y recibir mensajes, es decir, tienen funciones simbólicas. Según García Canclini, el consumo se realiza como parte de la racionalidad comunicativa e integrativa de la sociedad y es configurador de las identidades.

El autor señala que el contexto de la sociedad globalizada, con sus mercados transnacionales y las tecnologias masivas de comunicación que han transformado al mundo en un pueblo chico, las identidades se han desterritorializado. Hoy la cultura es un proceso de ensamblado multinacional, una articulación flexible de partes, un montaje de rasgos que cualquier ciudadano de cualquier país, religión o ideología puede leer o usar. Por primera vez en la historia la mayoría de los bienes y los mensajes que se reciben en cada nación no son producidos en su propio territorio, proceden del sistema internacional de producción y difu- 
sión. Con ello, los referentes tradicionales de la identidad -lengua, objetos, costumbres- son sustituidos por bienes y mensajes de consumo de este mercado internacional. Así, hoy es probable que dos golfistas aficionados o dos fanáticos del rock que viven separados por miles de kilómetros uno del otro compartan más elementos culturales que un golfista y un rockero vecinos de departamento. Si las identidades modernas eran territorriales y casi siempre monolingüísticas, las identidades posmodernas son transterritoriales y casi siempre multilingüísticas. En vez de basarse en la comunicación oral y escrita y en la interacción personal, operan sobre los medios tecnológicos de comunicación, de la industria cultural y el consumo diferido y segmentado de bienes, De allí que, de acuerdo al autor, la definición socioespacial de la identidad, referida a un territorio particular, necesite complementarse con una definción sociocomunicacional. Las sociedades civiles aparecen cada vez menos como comunidades nacionales, entendidadas como unidades territoriales, lingüísticas y políticas. Se manifiestan, más bien, como comunidades interpretativas de consumidores, es decir, conjuntos de personas que comparten gustos y pactos de lectura respecto ciertos bienes (gastronómicos, deportivos, musicales) que les dan identidades compartidas.

La felicidad del marco conceptual que emplea García Canclini puede cuestionarse. ¿Es posible considerar al consumo como la principal forma de integración cultural? En mi opinión, más que una lectura literal, el modo como García Canclini utiliza el concepto de consumo requiere de una lectura retórica. El autor trabaja con una hipérbole, que destaca por la vía de la exageración el lugar creciente que ocupa el consumo en nuestra sociedades. Asi, 10 que "Consumidores y ciudadanos" nos propone es una invitación a reflexionar e investigar sobre el desarrollo de las identidades culturales en el contexto de un mundo cada vez más globalizado y gobernado por la lógica del mercado transnacional. 